\title{
Onset of Manic Episode during Chemotherapy with 5-Fluorouracil
}

\author{
Jee Hyun Ha ${ }^{1}$, Dae-Yong Hwang ${ }^{2}$, Jaehak Yu${ }^{1 凶}$, Doo-Heum Park ${ }^{1}$ and Seung-Ho Ryu ${ }^{1}$ \\ ${ }^{1}$ Departments of Psychiatry and ${ }^{2}$ Surgery, School of Medicine, Konkuk University, Seoul, Korea
}

The authors report a case of 5-Fluorouracil (5-FU) induced manic episode in an elderly female without any previous psychiatric history. The patient presented manic symptoms after 4 th cycle of 5-FU chemotherapy after surgery of rectal cancer. After cessation of chemotherapy and administration of olanzapine and divalproex sodium, symptoms were subsided within 10 days.

Psychiatry Investig 2011;8:71-73

Key Words Manic episode, Colon cancer, 5-FU, Chemotherapy.

\section{INTRODUCTION}

Patients generally have chemotherapy after surgery for cancer, regardless of its stage. Chemotherapy usually causes several side effects, such as nausea, hair loss, and fatigue. The central nervous system is relatively safe from such toxicity because the blood-brain barrier protects it, and it has a slower cell proliferation rate. Nevertheless, chemotherapy agents can cause neurological and psychiatric complications.

Introduced in 1958, 5-Fluorouracil (5-FU) is one of the most common chemotherapeutic agents. It has been widely used to treat solid organ tumors, such as tumors of the colon, rectum, breast, pancreas, and stomach. Its usual side effects are gastrointestinal symptoms, alopecia, cardiotoxicity, and neutropenia. Although neuropsychiatric complications have not been common, physicians have reported leukoencephalopathy, ${ }^{1}$ depression, ${ }^{2}$ organic mental disorder, ${ }^{3}$ psychosis, ${ }^{4}$ and mania ${ }^{5}$ as side effects.

We report the case of a woman who developed an acute manic episode after receiving 5-FU chemotherapy during treatment for rectal cancer.

Received: September 27, 2010 Revised: October 27, 2010

Accepted: November 15, 2010 Available online: February 25, 2011

$\triangle$ Correspondence: Jae Hak Yu, MD, PhD

Department of Psychiatry, School of Medicine, Konkuk University, 4-12 Hwayang-dong, Gwangjin-gu, Seoul 143-729, Korea

Tel: +82-2-2030-7566, Fax: +82-2-2030-7748, E-mail: drjaehakyu@yahoo.co.kr (a) This is an Open Access article distributed under the terms of the Creative Commons Attribution Non-Commercial License (http://creativecommons.org/licenses/bync/3.0) which permits unrestricted non-commercial use, distribution, and reproduction in any medium, provided the original work is properly cited.

\section{CASE}

In January 2010, a 77-year-old female underwent a colonoscopy due to an intermittent anal bleeding episode. The test found a rather freely-movable, $1 \mathrm{~cm}$ ulcerofungating mass in the left anterior side of the anus, $1 \mathrm{~cm}$ above the anal verge. Colonoscopic biopsy confirmed an adenocarcinoma. There was no sign of metastasis in her abdominal computed tomography (CT) or whole body positron emission tomography scan. On January 18, 2010, she underwent a transanal local excision under general anesthesia. The final pathology revealed a submucosal invasion by the tumor and a lymphatic invasion by tumor cells. However, the patient and her family declined a further curative radical surgery. Therefore, we recommended adjuvant radiotherapy and chemotherapy as the alternative management. She received radiotherapy, scheduled as 28 sessions, whole-pelvis at 4,500 cGy and tumor bed boost at $540 \mathrm{cGy}$, from February 9th to March 22nd. During the same period, she received intravenous chemotherapy, in the form of $790 \mathrm{mg}$ $\left(500 \mathrm{mg} / \mathrm{m}^{2}\right)$ fluorouracil $(5-\mathrm{FU})$ and $32 \mathrm{mg}\left(20 \mathrm{mg} / \mathrm{m}^{2}\right)$ calcium folinate, for 5 consecutive days at 3-week intervals. Starting February 16th, she also received the antiemetic ondansetron.

After her 4th 5-FU and folinate calcium chemotherapy cycle on May 15th, her behavior changed rapidly. That evening, her mood was elated and talkative. She called a friend and asked to visit in the middle of night, around $3 \mathrm{am}$. Her voice became louder and her need to sleep decreased. The next day, she was still anxious and talkative as compared to her previous character. She became more impulsive and sometimes offered verbal assaults. Her mood was labile, and she wrote a will and 
then insisted that she was superior to the president of the Republic of Korea. Her family took her a local clinic, which gave her a sedative, but her mood and behavior displayed no remarkable improvement.

Finally, she came to the hospital, and the staff surgeon consulted the psychiatrist, who decided to admit her on May 25th. She had no family history of psychiatric illness or previous history of psychiatric treatment. On admission, her consciousness was clear, and orientation was intact. Her mood was elated, euphoric, and labile. Her pressure of speech and inattention made it difficult to carry out her interview. She was easily distracted by environmental stimuli and expressed energetic interest in the psychiatric ward. She had grandiose delusions, such as insisting she was stronger than the president of the Republic of Korea was. There was no evidence of auditory or visual hallucinations. Her neurological examination was normal. A brain magnetic resonance imaging (MRI) showed no evidence of metastasis or any signs of acute infarct or hemorrhage. There were chronic infarcts in the right frontal periventricular white matter and several small, chronic, ischemic foci in the subcortical white matter on both sides. These findings did not match her psychiatric symptoms. A routine blood test showed mild anemia $(\mathrm{Hb}=10.7 \mathrm{~g} / \mathrm{dL})$.

Our diagnostic impression was secondary manic episode due to substance (ICD-10 diagnosis, organic manic disorder F06.30). We prescribed olanzapine ( $5 \mathrm{mg} /$ day), divalproex sodium ( $250 \mathrm{mg} /$ day), and lorazepam ( $2 \mathrm{mg} /$ day). Then, after she had been hospitalized 5 days, we increased the dose to $10 \mathrm{mg}$ olanzapine and 1,000 mg divalproex sodium. We discontinued the lorazepam after the 2nd day. She was still in a manic state, with hyperactivity, grandiose ideation, insomnia, and labile mood. After her 10th day in the hospital, we increased her medication to $20 \mathrm{mg}$ /day olanzapine and $1,000 \mathrm{mg} /$ day divalproex sodium. After this 10th day, her mood gradually calmed down, and she started to sleep without interruption or extra medication. She could partially recall her symptomatic behaviors of 2 weeks ago and expressed feelings of shame. We decreased her medication to $15 \mathrm{mg}$ /day olanzapine and 1,000 $\mathrm{mg} /$ day divalproex sodium. She gradually returned to a normal range of moods, sleep pattern, and psychomotor speed. We conducted psychological tests during her admission day. Her IQ was average (total score $=98$ ), and her attention span and executive functioning were within normal ranges. The Bender-Gestalt test revealed no sign of organic brain damage. Minnesota Multiphasic Personality Inventory profile showed hyperactivity and a higher energy level, as the increased 9th factor.

On June 19th, she left the hospital with the manic episode in full remission. She did not show any extraordinary behavior, flight of ideas, or cognitive deficits. Her final medication was olanzapine, $10 \mathrm{mg} /$ day, and divalproate, $1,000 \mathrm{mg} /$ day. $\mathrm{Al}-$ though she was scheduled to undergo more chemotherapy, she and her family declined this idea, and her physician respected their decision. She visited the outpatient clinic one week and again one month after discharge. Her mood remained stable and euthymic. She had been taking her medications, with olanzapine at $5 \mathrm{mg} /$ day and divalproex sodium still 1,000 $\mathrm{mg} /$ day. Her manic episode was still in remission. We scheduled her to receive the medication for several months, to prevent a possible relapse.

\section{DISCUSSION}

Though the patient received additional folinate calcium and ondansetron, we did not assume they were directly associated with her development of manic symptoms. As radiotherapy was limited to the rectal lesion, it could not affect the central nervous system. Therefore, the chemotherapy series using 5-FU was associated with her abrupt manic episode.

Fluorouracil's mechanism of action blocks DNA synthesis by decreasing thymidine monophosphate formation through the inhibition of thymidylate synthetase. As 5-FU can easily penetrate the blood-brain barrier, it is reportedly associated with several neurological complications, including parkinsonian syndrome, oculomotor disturbance, and peripheral neuropathy. ${ }^{1}$ The ending metabolite of 5-FU is fluorocitrate; we regarded its inhibition of aconitase in the Krebs cycle, resulting in citrate accumulation in the neurons, as the neurotoxicity mechanism. ${ }^{6}$ Fluorouracil itself did not correlate with the neurotoxicity. ${ }^{7}$ Previous cases studies reported leukoencephalopathy in brain CTs. However, this case showed no evidence of leukoencephalopathy on a brain MRI. We attribute her vulnerability to psychiatric symptoms to her age, because 5-FU side effects are common in the elderly. ${ }^{8}$

Accumulation of 5-FU is one possible cause of such a secondary manic episode, via injury to several brain structures and neurotransmitter pathways. Secondary mania should be diagnosed in a case of no previous affective illness history and no confusional state. This patient's onset age was considerably older than the typical age for a primary manic episode. ${ }^{9}$

There are several possible mechanism related to secondary mania. First, it can develop after a neuronal injury focuses on right side limbic area lesion. And the right basotemporal and orbitofrontal cortex area is more likely to correlate with a bipolar episode, whereas a right side cortical injury alone occurs in association with unipolar secondary mania. ${ }^{10}$ An orbitofrontal cortex lesion can cause development of irritability, labile mood, euphoria, and inappropriate social behavior. ${ }^{11}$ Additionally, dysfunction of the hypothalamic area can lead to insomnia and dysregulation of appetite and sleep..$^{12}$ At the 
neurotransmission level, the interactions of serotonin, dopamine, norepinephrine, and acetylcholine through the orbitofrontal-subcortical network are associated with development of manic symptoms. ${ }^{9}$

Based on these research findings, we thought that 5-FU's neurotoxicity accumulated during the 4 chemotherapy cycles, then a subtle change in the orbitofrontal-subcortical network, correlated with the dopamine and serotonin system, and reversible damage to the right cortical and limbic area caused a rapid manic episode. The manic episode subsided after discontinuation of 5-FU and administration of antipsychotic drugs. Furthermore, we thought the additional factors, such as her lack of any record of previous mood episodes, her rapid remission, the reversibility of her symptoms, and lack of cognitive change showed the manic episode developed due to an exogenous substance. Moreover, 5-FU-related neurotoxicity is dose- and schedule-dependent and reversible upon discontinuation of the medication. ${ }^{1}$

We reported that the chemotherapeutic agent 5-FU can induce, not only neurological symptoms, but also psychiatric symptoms. Clinicians need to consider the possible development of psychosis or mood symptoms in cases of 5-FU usage.

\section{REFERENCES}

1. Choi SM, Lee SH, Yang YS, Kim BC, Kim MK, Cho KH. 5-fluoroura- cil-induced leukoencephalopathy in patients with breast cancer. J Korean Med Sci 2001;16:328-334.

2. Park HJ, Choi YT, Kim IH, Hah JC. A case of reversible dementia associated with depression in a patient on 5-FU or its analogue drugs. J Korean Neuropsychiatr Assoc 1987;30:199-202.

3. Choi BS, Cheon HJ, Han SH. A case of 5-FU induced organic mental disorder. J Korean Neuropsychiatr Assoc 1986;25:319-322.

4. Fora A, Alabsi E, Fakih M. A case of 5-fluorouracil-induced acute psychosis. Clin Colorectal Cancer 2009;8:166-168.

5. Pacchiarotti I, Mazzarini L, Pellegrini P, Venturelli V, Sani G, SánchezMoreno J, et al. A case of manic episode during treatment with 5-fluorouracil, epirubicin and cyclophosphamide for breast cancer. Gen Hosp Psychiatry 2007;29:461-463.

6. Park YM, Kwon HY, Kim HW, Kim DK. A case of diffuse leukoencephalopathy caused by 5-Fluorouracil. J Korean Neurol Assoc 1995;13: 1007-1010.

7. Köenig H, Patel A. Biochemical basis for fluorouracil neurotoxicity. The role of Krebs cycle inhibition by fluoroacetate. Arch Neurol 1970; 23:155-160.

8. Köhne CH, Grothey A, Bokemeyer C, Bontke N, Aapro M. Chemotherapy in elderly patients with colorectal cancer. Ann Oncol 2001;12: 435-442.

9. Soars JC, Gershon S. Bipolar disorders: basic mechanisms and therapeutic implications. Marcel Dekker, NY; 2000.

10. Starkstein SE, Fedoroff P, Berthier ML, Robinson RG. Manic-depressive and pure manic states after brain lesions. Biol Psychiatry 1991;29: 149-158.

11. Cummings JL. Frontal-subcortical circuits and human behavior. J Psychosom Res 1998;44:627-628.

12. Cummings JL. Organic psychoses. Delusional disorders and secondary mania. Psychiatr Clin North Am 1986;9:293-311. 